\title{
Reflections on the Nordic Journal of STEM Education: Strengthening a Nordic STEM education community
}

\author{
Kristina Edström \\ KTH Royal Institute of Technology, Stockholm, Sweden
}

This journal is a new arena for "scholarship that matters", particularly welcome due to its Nordic scope, STEM education focus, open access, and language options. By disseminating ideas, experiences, and credible evidence, it can help improve our understanding of consequential issues and support the advancement of education. By offering opportunities to learn about and build upon the work of others, it can strengthen the community, and increase the legitimacy of our work. Here, some reflections are made on the positioning and potentials of the journal.

\section{WHY NORDIC?}

It could be said that a journal shows "who's who" in the field, thereby creating opportunities for discovering people who express intriguing knowledge and significant ideas, and for making yourself known to others. It helps identify peers for exchanging ideas and knowledge, and for collaborating. This is particularly valuable in a community where many individuals work relatively alone in their home institution and therefore can truly prosper from external networking. Scholars may suddenly find that they share interests with colleagues, be they working in the next corridor, or in other institutions and countries.

The Nordic scope of this journal is particularly welcome (also discussed in Edström, Kolmos, Malmi, Bernhard, \& Andersson, 2016). While there are national conferences in Norway, Sweden and Denmark ${ }^{1}$, meetings across these borders are less available. In fact, meetings between Nordic scholars probably happen more often in larger international settings. Nordic knowledge exchange could play a particularly valuable role, since the considerable similarities in the educational systems and cultures should make the work relatively applicable. This journal can potentially reach a broader audience among Nordic colleagues, especially given the open access and the opportunity to write in the Scandinavian languages. It also fills the need for an intermediate outlet, for the common situation when we have something to say which is well worth the effort to make a proper journal publication, but for various reasons we may not want to take the step to international journals.

\section{WHY STEM?}

A key premise for the STEM scope of this journal is that if we are to analyse and improve learning, we need both general insights into teaching and learning and an understanding of the specific content and context of education. It is necessary to understand the nature of learning that our particular students are grappling with, the STEM content. The STEM context is also important, such as insights into the culture and traditions of our educational programs, the organisation of our institutions, and the working life of our graduates. In the United States, the National Research Council (2012) stated that high-quality discipline-based educational research "combines expert knowledge of a science or engineering discipline, of the challenges of learning and teaching in that discipline, and of the science of learning and teaching generally". The idea is essentially that educational research is more likely to result in meaningful improvements in education when it is conducted within a disciplinary setting, because it will focus on issues that are seen as relevant in the disciplinary community, and produce results that can be accepted as legitimate (see for instance Henderson et al., 2017; Singer \& Smith, 2013).

STEM education research comprises several large fields, each with its own history and communities. There are specialised conferences and journals for physics education, computer science education, mathematics education, chemistry education, engineering education, technology and design education,

\footnotetext{
${ }^{1}$ For instance MNT-konferansen; Nätverk och Utveckling, NU, and Utvecklingskonferensen för Sveriges Ingenjörsutbildningar; Dansk Universitetspædagogisk Netværk, DUN.
} 
etc. While specialisation has many advantages, it also creates a separation that tends to hide that we have many issues in common, across the disciplinary boundaries. We also collaborate in educational programs and share an ambition to advance STEM education. The establishment of a joint arena should be seen as an invitation to explore and report on issues of common interests, to find common ground and joint action, but also to be inspired by each other's more specific toolboxes and findings.

Table 1. Criteria for the maturity of a discipline (Fensham, 2004).

\begin{tabular}{|c|c|c|}
\hline Structural Criteria & Research criteria & Outcome Criteria \\
\hline $\begin{array}{ll}\text { - } & \text { Academic recognition } \\
\text { - } & \text { Research journals } \\
\text { - } & \text { Professional associations } \\
\text { - } & \text { Research conferences } \\
\text { - } & \text { Research centres } \\
\text { - } & \text { Research training }\end{array}$ & $\begin{array}{ll}\text { - } & \text { Scientific knowledge } \\
\text { - } & \text { Asking questions } \\
\text { - } & \text { Conceptual and theoretical } \\
\text { - } & \text { development } \\
\text { - } & \text { Research methodologies } \\
\text { - } & \text { Modession publications } \\
\text { - } & \text { Seminal publications }\end{array}$ & - Implications for practice \\
\hline
\end{tabular}

When Fensham (2004) described the evolution of the science education research field, he identified indicators of maturity (see Table 1). These criteria can be used to consider the current state of the Nordic STEM area. According to the structural criteria, the establishment of this journal is in itself a sign of maturity of Nordic STEM education. A journal should be seen as one of the necessary infrastructures creating a field, in intense interplay with the others. For instance, $\mathrm{PhD}$ education fosters new scholars, while journals and conferences help scrutinise and provide feedback on their work, with senior scholars filling the roles as supervisors, reviewers, opponents and committee members. These structures are the very sites in which a research community negotiates what defines its work, values, identities and territories. What emerges from the definitional debates are agreements - more or less unanimous and more or less temporary - regarding what Fensham called the research criteria: what knowledge is recognised as established, what research questions are interesting, what approaches, conceptual frameworks and methodologies are useful and acceptable, and what constitutes really good work.

Fensham's criteria are however somewhat lopsided. While the research criteria, all referring to aspects of scholarliness, are relatively well specified, the same is not true for the outcome criteria, the implications for practice. To make it possible to accommodate contributions that are useful for improving STEM education, we need a deeper understanding of impact for practice, so we can operationalize the outcome criteria and be able to judge these aspects. Otherwise the risk is that work will be assessed mainly through the more familiar lenses of formal scholarliness, leaving usefulness an empty and toothless concept, something we often say but seldom live.

\section{THE QUALITY CONTROL PROCESS OF A JOURNAL}

Setting quality standards is one of the important functions performed by a journal, through the selection of what to publish. In a journal, as in most processes under academic control, the quality mechanism works on a case-by-case basis in the peer review process. Therefore, a journal can never become better than the work of its reviewers. The success of this journal depends on recruiting reviewers who can work effectively, in full awareness of the ambitions of the journal. It requires a large pool, as each reviewer must be engaged only infrequently, allowing her or him to make the full effort required for each manuscript. Making thorough, constructive and prompt reviews is to make an important contribution to the field. Although it is always tough to take on yet another task, reviewing is - perhaps not every time, but on the whole and over time - highly educating and rewarding for the quality of one's own work.

The view on what characterises good work, worthy of publication in the Nordic Journal of STEM Education, needs to be thoughtfully and widely discussed and transparently communicated. This is important, as we otherwise risk using random and subjective criteria, or unquestioning acceptance of one dominant paradigm (Bernhard and Baillie 2016). The quality criteria for the Nordic Journal of STEM Education, enacted in the review process, should reflect both usefulness and scholarliness. 
Scholarliness is always necessary for establishing credibility and trustworthiness. This goes for both categories of submission, the "scholarship" as well as the "best practice" contributions, but to different degrees. There is however no point in adding the trappings of research as superficial decorations, and reviewers should see through such attempts. Usefulness is important as the primary motivation for this type of scholarship, but it should not remain merely a mantra; we need to develop a sophisticated understanding, as well as the ability to assess it. In this journal, many different dimensions of usefulness could be recognised. Some manuscripts may have the power to inspire, some contain something directly actionable, some strengthen our capacity to interpret and handle issues, some help us design and plan interventions that are feasible and sustainable, some call attention to the most urgent challenges, and some may do all of these things simultaneously. Given how much knowledge, inspiration, and evidence that is already published without being considered in educational practice, it is however not sufficient to look only for the mere potential to create impact. If educational scholarship should in reality come to support educational improvement, one consequence for the journal is that the boundary between research and development needs to be kept permeable and fluid. It needs to welcome boundary work, and boundary people.

\section{COMBINING SCHOLARLINESS AND USEFULNESS}

The discussion above should not imply that there is a fundamental trade-off between scholarliness and usefulness. In a similar debate in the past, Harvey Brooks, a physicist and Dean of Engineering and Applied Sciences at Harvard University, helpfully pointed out that basic research and applied research are not necessarily opposites:

Work directed toward applied goals can be highly fundamental in character in that it has an important impact on the conceptual structure or outlook of a field. Moreover, the fact that research is of such nature that it can be applied does not mean that it is not also basic. (Brooks, 1967)

Brooks used Pasteur as an example of how work can be ground-breaking in both a practical and theoretical sense. Interestingly, Pasteur always had practical problems as the starting point, such as helping a local brewer to control fermentation, to reliably produce alcohol and not lactic acid. When Pasteur showed that the fermentation depended on which type of yeast or bacteria was present, he thereby proved conclusively that microbes were responsible for these processes. In addition to indicating solutions to the brewer's problem, his discovery started a new scientific field microbiology. Pasteur continued to work on practical problems, for instance devising how to preserve food by heating it to kill microbes (pasteurisation) and developing vaccines for animals and humans. Hence, Pasteur's practice-oriented and useful work created significant new scientific insights. Building on Brooks' argument, Stokes (1997) devised a model with the "consideration for use" on one axis and the "quest for fundamental understanding" on the other (see figure 1).

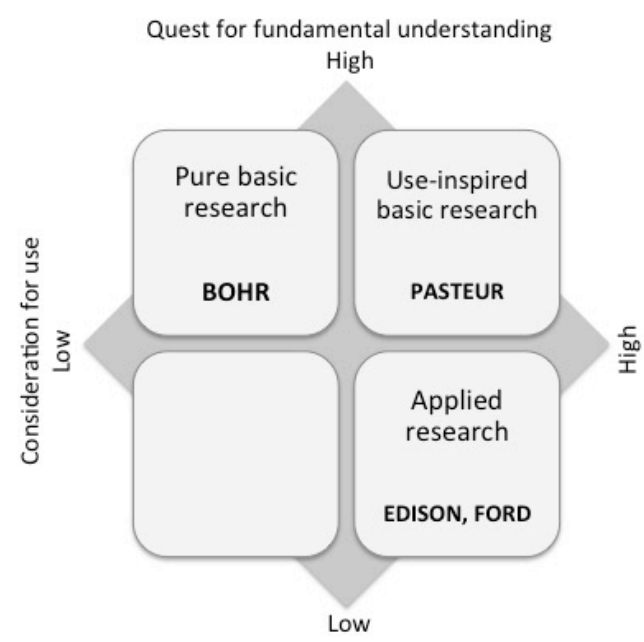

Figure 1. Pasteur's Quadrant (based on Brooks, 1967, and Stokes, 1997, and reproduced from Edström, 2017). 
The quadrant where both ambitions are fulfilled is labelled Pasteur's quadrant. In Edison's quadrant, the focus is only on solving the problem. Stokes points out how "Edison kept his co-workers from pursuing the deeper scientific implications of what they were discovering in their rush toward commercially profitable electric lighting". Bohr's quadrant is the pure basic science, or knowledge for its own sake. Here, the researcher is seeking only fundamental understanding, unconcerned with its potential use. This is not to say that such research cannot become useful, but the premise is that someone else can figure out later whether and how the new knowledge can be used.

The challenge here should thus be how to make one's work interesting and valuable to practitioners, while also contributing to our understanding within the field. In the debates within engineering education research, Streveler and Smith (2006) reminded us that this is the same ideal as for engineering science, and they argue: "engineering education research needs to be in Pasteur's Quadrant, that is, it needs to build theory and inform practice".

\section{WRITING FOR THE JOURNAL}

While the importance of reviewers was mentioned above, it is also true, and even more obvious, that $a$ journal can never become better than the work of its authors. Possibly the best thing about writing a manuscript is that it forces authors to use their full capacity and to practice good intellectual habits: carefully choosing a significant and engaging topic and deciding how to approach it; reading, processing and presenting existing literature; analysing and reflecting on experiences; demonstrating a systematic approach; clearly formulating our arguments and showing how the conclusions were built; considering and acknowledging limitations; and meticulously documenting the work and communicating it. As an extra bonus, reviewers and editors provide thoughtful feedback on the manuscript, challenging authors to make an extra effort before the paper is let out in public, where the open scrutiny continues. While there are painful components in this process, even ultimately rejection, it is intended to bring out the best in everyone, and create the best end product, making it stimulating and enjoyable to follow the results, both the people and their work.

\section{References}

Bernhard, J., \& Baillie, C. (2016). Standards for Quality of Research in Engineering Education. International Journal of Engineering Education, 32(6), 2378-2394.

Brooks, H. (1967). Applied Research, Definitions, Concepts, Themes Applied science and technological progress: A report to the Committee on Science and Astronautics, U.S. House of Representatives (pp. 21-55). Washington, DC.: National Academy of Sciences.

Edström, K., Kolmos, A., Malmi, L., Bernhard, J., \& Andersson, P. (2016). A bottom-up strategy for establishment of EER in three Nordic countries - the role of networks. European Journal of

Engineering Education, 1-16. doi:10.1080/03043797.2016.1190956

Edström, K. (2017). The role of CDIO in engineering education research: combining usefulness and scholarliness. European Journal of Engineering Education.

Fensham, P. J. (2004). Defining an identity: The evolution of science education as a field of research. Dordrecht: Springer Science \& Business Media.

Henderson, C., Connolly, M., Dolan, E. L., Finkelstein, N., Franklin, S., Malcom, S., Rasmussen, C., Redd, K., John, K. S. (2017). Towards the STEM DBER Alliance: Why We Need a Discipline-Based STEM Education Research Community. Journal of Engineering Education, 106(3), 349-355.

doi:10.1002/jee.20168

National Research Council. (2012). Discipline-based education research: Understanding and improving learning in undergraduate science and engineering. S. R. Singer, N. R. Nielsen, \& H. A. Schweingruber (Eds.) Washington, DC: The National Academies Press. Retrieved from www.nap.edu/catalog.php?record_id=13362 
Singer, S., \& Smith, K. A. (2013). Discipline-Based Education Research: Understanding and Improving Learning in Undergraduate Science and Engineering. Journal of Engineering Education, 102(4), 468471. doi:10.1002/jee.20030

Stokes, D. E. (1997). Pasteur's quadrant: Basic science and technological innovation. Washington, DC: Brookings Institution Press.

Streveler, Ruth A., \& Smith, K. A. (2006) Conducting rigorous research in engineering education. Journal of Engineering Education, 95(2), 103-105. 